UCRL-JC-130305

PREPRINT

\title{
Investigation of Range Extension with a Genetic Algorithm
}

\author{
A. S. Austin
}

This paper was prepared for and presented at the 7th AIAA/USAF/ISSMO Symposium on Multidisciplinary Analysis and Optimization

St. Louis, MO

September 2-4, 1998

March 4, 1998

This is a preprint of a paper intended for publication in a journal or proceedings. Since changes may be made before publication, this preprint is made available with the understanding that it will not be cited or reproduced without the permission of the author. 


\section{DISCLAIMER}

This document was prepared as an account of work sponsored by an agency of the United States Government. Neither the United States Government nor the University of California nor any of their emplnyees, makes any warranty, express or implied, or assumes any legal liability or responsibility for the accuracy, completeness, or usefulness of any information, apparatus, product, or process disclosed, or represents that its use would not infringe privately owned rights. Reference herein to any specific commercial product, process, or service by trade name, trademark, manufacturer, or otherwise, does not necessarily constitute or imply its endorsement, recommendation, or favoring by the United States Government or the University of California. The views and opinions of authors expressed herein do not necessarily state or reflect those of the United States Government or the University of California, and shall not be used for advertising or product endorsement purposes. 


\title{
INVESTIGATION OF RANGE EXTENSION WITH A GENETIC ALGORITHM
}

\author{
Scott Austin \\ austin16@llnl.gov
}

To be Submitted to the AIAA/USAF/ISSMO

Symposium on Multidisciplinary Analysis

and Optimization

September 2-4, 1998

St. Louis, Mo. 
INVESTIGATION OF RANGE

EXTENSION WITH A

GENETIC ALGORITHM

\author{
Scott Austin * \\ austin16@llnl.gov
}

\subsection{INTRODUCTION}

Range optimization is one of the tasks associated with the development of costeffective, stand-off, air-to-surface munitions systems. The search for the optimal input parametcrs that will result in the maximum achievable range often employ conventional Monte Carlo techniques. Monte Carlo approaches can be time-consuming, costly, and insensitive to mutually dependent parameters and epistatic parameter effects. An alternative search and optimization technique is available in genetic algorithms.

In the experiments discussed in this report, a simplified platform motion simulator was the fitness function for a genetic algorithm. The parameters to be optimized were the inputs to this motion generator and the simulator's output (terminal range) was the fitness measure. The parameters of interest were initial launch altitude, initial launch speed, wing angle-of-attack, and engine ignition time.

The parameter values the GA produced were validated by Monte Carlo investigations employing a full-scale six-degree-of-freedom (6 DOF) simulation. The best results produced by Monte Carlo processes using values based on the GA derived parameters were within

*This work was performed while the author was employed with GEC-Marconi Dynamics, Westlake Village, CA. The author is now employed by the California Management Group, and serves as a contract senior software engineer on the Atomic Vapor Laser Isotope Separation project at the Lawrence Livermore National Laboratory.
$1 \%$ of the ranges generated by the simplified model using the evolved parameter values.

This report has five sections. Section 2 discusses the motivation for the range extension investigation and reviews the surrogate flight model developed as a fitness function for the genetic algorithm tool. Section 3 details the representation and implementation of the task within the genetic algorithm framework. Section 4 discusses the results. Section 5 concludes the report with a summary and suggestions for further research.

\subsection{RANGE EXTENSION SIMULATION}

I,ow cost, light weight, in-flightdeployable wing kits are a means of extending the range of existing air-borne munitions ${ }^{5,7}$. The benefits of range extension are well known. Range extension kits are generally compatible with several existing and planned items in the US armed force's inventory. The purpose of the wing kit is to provide enhanced range performances with a minimum of structural changes to these weapons.

For the genetic algorithm investigation under discussion, development of a simple trajectory model fitness function for the genetic algorithm was not a difficult exercise, although a full scale 6 DOF was available, and was used with the Monte Carlo simulations. Figure 1 depicts the geometry of the dynamical system under consideration.

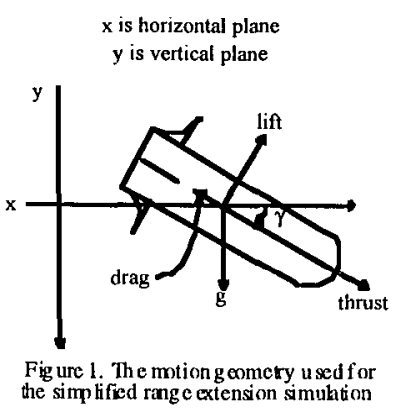

The equations of motion used in conjunction with the vehicle geometry shown in Figure 1 are: 
weapon $\mathrm{x}$ and $\mathrm{y}$ acceleration;

$$
\begin{aligned}
& a_{w x}=\frac{g}{W}(((\text { thrust }- \text { drag })(\cos \gamma))+(\text { lift }(\sin \gamma))) \\
& a_{w y}=\frac{g}{W}(W+((\text { thrust }- \text { drag })(\sin \gamma))-(\text { lift }(\cos \gamma)))
\end{aligned}
$$

drag and lift:

$$
\begin{gathered}
\text { drag }=c_{d} \frac{\rho}{2} v_{T}^{2} A \\
\text { lift }=c_{l} \frac{\rho}{2} v_{T}^{2} A
\end{gathered}
$$

The coefficients of drag is $c_{d}$, and lift is $c_{l} . \rho$ is air density as a function of altitude ${ }^{\dagger}, A$ is the cross-sectional area of the wing and $v_{T}$ is the total weapon velocity. From these basic equations, a range profile vs. altitude was computed with a one second resolution (the 6 DOF used a .01 second resolution). A representative trajectory is shown in Figure 2.

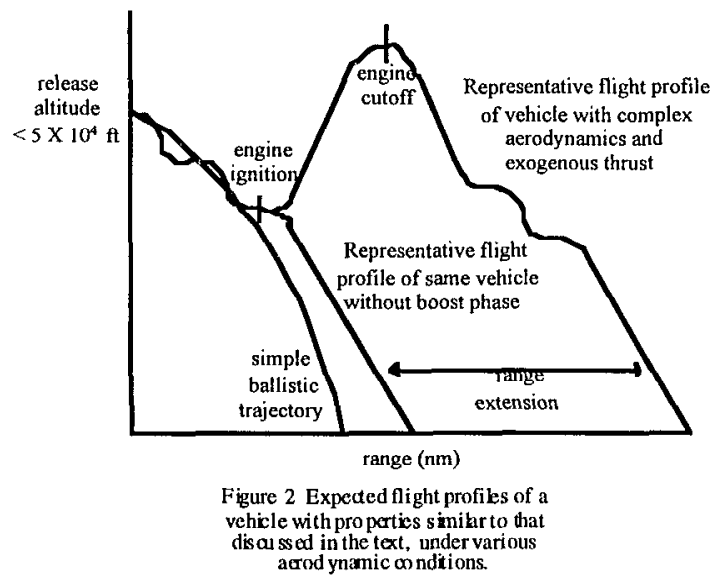

Trajectories with and without exogenous applied thrust are depicted. The primary parameters determining the total range of this system are: release altitude, engine ignition time (if applicable; thrust magnitude and

${ }^{\dagger}$ The aero data was modeled as fixed table values, and was derived from aero-data sources for an existing precision guided munition. duration are constant), wing angle of attack, and release velocity.

\subsection{GENETIC ALGORITHM IMPLEMENTATION}

Details of the genetic algorithm process are broadly available ${ }^{4}$. They are becoming increasingly visible in diverse areas such as pattern recognition ${ }^{6}$, engineering design ${ }^{3}$, engineering applications ${ }^{2}$, and human factors modeling ${ }^{1}$.

In summary, a genetic algorithm is a computational process using metaphors of simplified genetic and evolutionary principles to effect an efficient search through a complex problem space. Although there can be variations in the theme, the general procedure is to represent the solution structures of the task encoded as a linear, binary, "chromosome" (Figure 3). In concert with the bio-genetic and evolutionary implementation the concepts of variation and selection operate on the chromosomes to generate new populations.

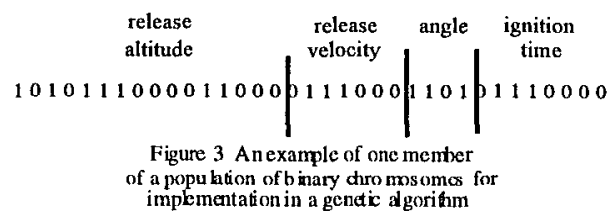

The creation of a new generation from the current one follows three steps:

1. Evaluation. Test each member according to an "environmental" performance criterion and assigned a scalar fitness measure.

2. Selection. Relative performance determines any member's frequency of reproduction in the population. Members are selected from the current population as parents. One chromosome may be a co-parent with several other chromosomes. 
3. Variation and Replacement. The process of variation is manifested by recombination and mutation.

Recombination is simulated by randomly paring members of the population, then selecting (also randomly) a crossover point. At this crossover point "genetic material" from one parent chromosome is selected from this point to the left, and genetic material from the other parent is selected from this point to the right. These two segments are recombined to produce an "offspring" to be a member of the next population. At this juncture a small factor of "point mutation" can be introduced.

\subsection{RESULTS}

Figure 4 is the evolutionary history for one experiment using the genetic algorithm for the range extension problem.

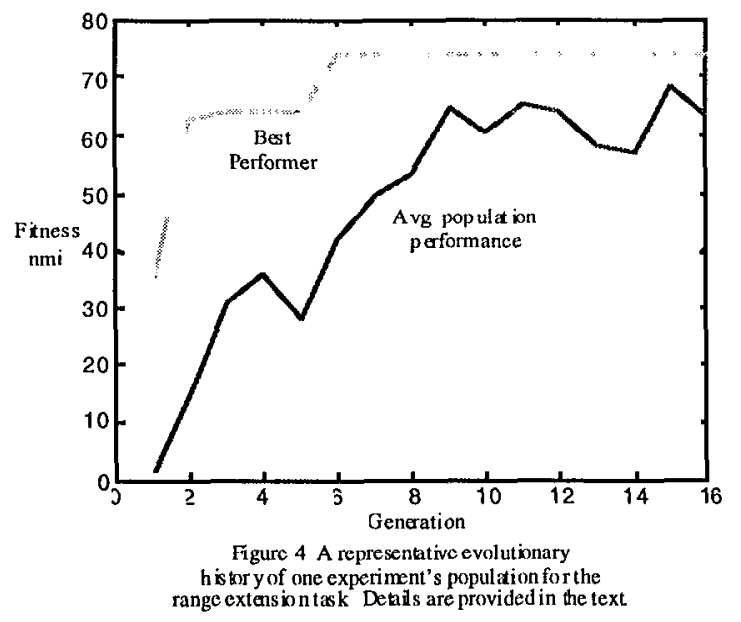

The upper trace in this figure is the best performer in each generation. The fitness measure is given in miles. The bottom scale is the number of generations the process was allowed to evolve. The lower trace represents each generation's average membership performance. Note that the best performer for this experiment was discovered as early as the 6 th generation. The population size of each generation was only 20 members. Over the 16 generations a total of 320 possible solutions were explored.

Figure 5 is the trajectory resulting from the parameters derived from the evolutionary process illustrated in the previous figure. The evolved conditions were: release altitude $=$ $38632 \mathrm{ft}$ (optimal $=40 \mathrm{kft}$ ), release velocity $=$ 1.05 mach (optimal), angle of attack $=4^{\circ}$ (optimal), and ignition time 90 seconds after release (optimal).

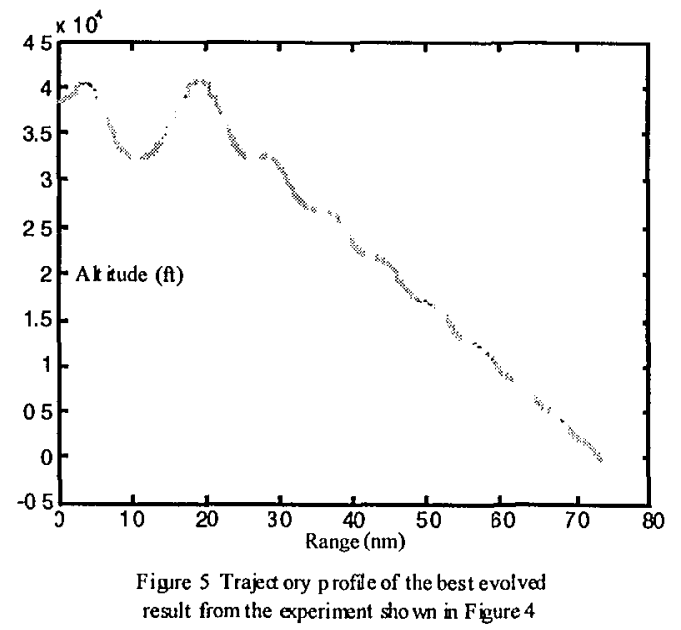

The near optimality of the parameters were validated by a Monte Carlo simulation to determine if they truly represented the mutually consistent best values. In this instance the values derived by the genetic algorithm solution were used as initial values and the neighborhoods about these values were searched for elements yielding better solutions.

It is interesting to note that evolved solution shown above required the testing of only 120 members of the population before a near optimal solution emerged. In other words, $\sim 1.2 \times 10^{2}$ members were tested out of a possible $3.4 \times 10^{10}$ elements or only $\sim 3.5 \mathrm{X}$ $10^{-7} \%$ of the problem space. In fact, the evolved solution above was slightly better than that generated by an independent Monte Carlo approach, i.e. a simulation where the initial starting parameters for the Monte Carlo 
solution were not cued by those derived from the genetic algorithm solution.

\subsection{CONCLUDING COMMENTS}

A natural continuation to the research presented here would be to investigate the impact of angle of attack variation over the course of a trajectory, specifically during the post-boost phase.

Figure 5 represents a signature common to this type of problem, i.e. where the transfer between the kinetic and potential energy of the descending object results in an non-optimal, dampened, oscillatory trajectory. Dynamic selection of wing angle of attack parameters over this portion of the flight path can eliminate this phenomena and result in a smooth transfer of energy and an extended trajectory.

Another is approach to be considered is evolution of neural network architectures. Neural networks are being actively scrutinized as providing flexible control strategies for rapidly changing environments. Genetic algorithms are finding increasing utilization as an alternative method for both the structural and parameter spccification of artificial neuronal structures ${ }^{8}$.

\section{REFERENCES}

1. Austin, A. S., "Parameter Estimation of a Human Factors Model Using Genetic Algorithms," Proceedings of the Sixth AIAA/USA/USAF/NASA/ISSMO

Symposium on Multidisciplincary Analysis and Optimization, (1996), AIAA.

2. Dasgupta, S. K., Michalewicz, Z., (Eds.) Evolutionary Algorithms in Engineering Applications, Springer-Verlag, Berlin (1997)

3. Gen, M., Cheng, R., Genetic Algorithms \& Engineering Design, John Wiley \& Sons, Inc. (1997)
4. Goldberg, D. E., Genetic Algorithms in Search Optimization \& Machine Learning, Addison-Wesley Publishing Company, Inc. Menlo Park, (1989).

5. Kroo, I., Gallman, J., and Stephen Smith, "Aerodynamic and Structural Studies of Joined-Wing Aircraft," AIAA Journal, Vol. 28, NO. 1, Jan 1991.

6. Pal, S. K., Wang, P. P., (Eds.) Genetic algorithms for pattern recognition, CRC Press, Inc. (1996).

7. Wolkovitch, Julian, "The Joined Wing: An Overview," Proceedings of the AIAA 23rd Aerospace Sciences Meeting, (1985), AIAA.

8. International Workshop on Combinations of Genetic Algorithms and Neural Networks (1992), IEEE Computer Society Press, Los Alamitos, CA. 


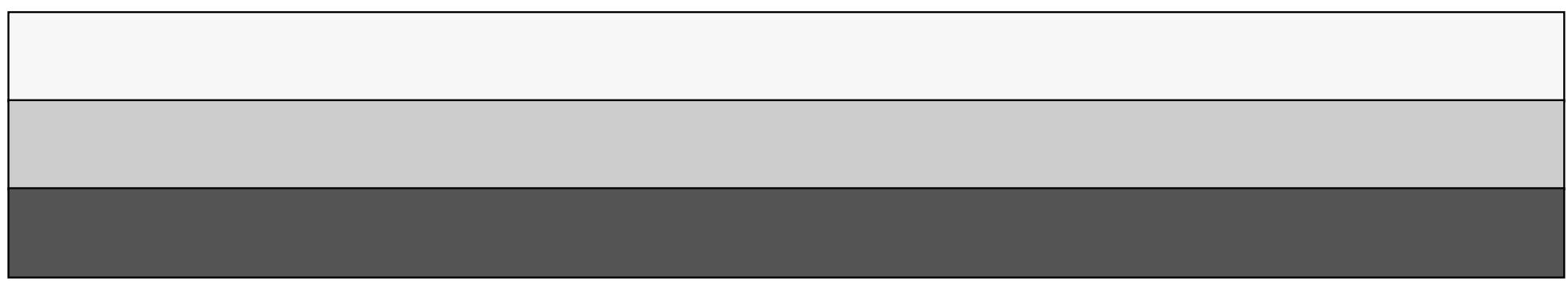

